\section{Tendencias en la circulación de programas televisivos en el Mercosur $^{1}$}

\section{RESUMO}

Este trabalho trata da análise da veiculação dos programas de TV produzidos pelos países membros do Mercosul. 0 objetivo é apresentar o mapa dos sistemas televisivos dos países que fazem parte do Bloco. Entre estes, há aqueles com produção de programação (Brasil e Argentina) e outros que importamna (Uruguai e Paraguai).

\section{ABSTRACT \\ This article analyses the broadcasting of tv programs in the Mercosul area. It shows that there are countries which mostly produce their own programs (like Brazil and Argentina) while others mostly import them (such as Uruguay and Paraguay). \\ PALAVRAS-CHAVE / KEY-WORDS \\ - Programas de tv (Tv programs) \\ - Difusão (Broadcasting) \\ - Mercosul (Mercosur)}

Nora Mazziotti

\section{Libertad Borda}

Carolina Heidenhain

María Laura Weiss

Universidad de Buenos Aires, Instituto de Investigación Gino Germani, Facultad de Ciencias Sociales.
I Introducción ${ }^{2}$

LOS MEDIOS DE COMUNICACIÓN tienen un rol crucial en los modos en que se reconfiguran las relaciones entre las naciones y su heterogeneidad interna (Murciano, 1996; Bustamante, 1993; Mc Quail, 1992) puesto que, como es sabido, proponen estructuras cognitivas y conforman parámetros perceptivos de las relaciones interculturales. El Mercosur -así como la formación de otros bloques económicosconstituye una de las transformaciones más importantes de la última década, por lo que el análisis de las maneras en que circula y se posiciona la programación televisiva producida en el área contribuye a un mejor conocimiento sobre los alcances y desafíos que conlleva el Tratado.

El objetivo del presente trabajo es indagar la configuración de la grilla - o parrilla - televisiva en cada país-miembro del Mercosur y la circulación de programas entre estos países. Por un lado, se debe destacar que la circulación de programas tiene una larga práctica, que antecede al Tratado (1991). La circulación se produce por razones netamente comerciales y ajenas a las políticas de integración, ya que las industrias audiovisuales fueron dejadas de lado en los protocolos del acuerdo. Las únicas políticas de integración abordadas hasta el momento tienen que ver con las bellas artes (Galperin, 1997).

Por otro lado, hay que tomar en cuenta que los países que integran el Mercosur presentan profundas asimetrías en lo que hace a sus industrias audiovisuales. Encontramos lo descripto por Roncagliolo (1996) para la totalidad de 
la industria audiovisual latinoamericana:

- Un país netamente exportador, Brasil, con una de las principales cadenas televisivas del mundo (la TV Globo).

- Un país incipientemente exportador, la Argentina.

- Dos países como Uruguay y Paraguay, que a lo largo de la historia han producido escasa programación propia, y menos aún, de ficción, que es la que sustenta el desarrollo de una industria de televisión.

A este panorama cabría agregar otro rasgo: con al desarrollo de la TV satelital, Argentina se convirtió en uno de los países con más alta tasa de conexión a la TV por satélite del mundo, con más del $60 \%$ de los hogares abonados a alguna empresa de cable. En cambio, la presencia del cable es mucho menor en los otros paísesmiembro, incluso en Brasil, donde ha tenido un crecimiento mucho más bajo de lo que se pronosticaba hace algunos años. Esta diferencia en la ecología audiovisual incidirá necesariamente en la conformación de la grilla de la televisión abierta.

Una de las hipótesis de este trabajo es que, si bien Brasil es uno de los máximos productores y exportadores a nivel mundial (la Rede Globo "ha llevado a Brasil al cuarto lugar como productor y tercero como exportador audiovisual", Roncagliolo, 1996: 46), en el Mercosur el panorama televisivo presenta matices diferentes, como se verá en el cotejo de las distintas grillas en función del origen de las producciones.

Una primera observación acerca de las características de la circulación de programación televisiva en el Mercosur tiene que ver con un rasgo no específico de las industrias audiovisuales latinoamericanas, como lo es la capacidad de circulación de ciertos géneros, o dicho de otro modo, la existencia de géneros que pueden ser emitidos en diferentes países manteniendo un nivel aceptable de audiencia (desde el punto de vista comercial). Los géneros periodísticos (tanto informativos como de opinión, etc.) son producidos en cada país, incluso en muchas ciudades o regiones, y no suelen exportarse. Pueden llegar a introducirse a través del cable e incluso tener cierta importancia (como es el caso de CNN), debido a la necesidad de este medio de cubrir diferentes nichos de audiencias. No obstante, se ha comprobado que las audiencias priorizan siempre la información de carácter local. El entretenimiento presenta mayores posibilidades de migración; la ficción se destaca como zona privilegiada, pero también pueden circular otros formatos, como programas de juegos y variedades.

Tradicionalmente, debido a la ausencia de producción ficcional, por los altos costos en relación con el tamaño de su mercado y de la inversión publicitaria, Paraguay y Uruguay se nutrieron de ficciones provenientes principalmente de Argentina. Señales argentinas "exportan sus telenovelas, comedias, programas de variedades. Particularmente a los países vecinos como Chile, Paraguay y Uruguay, con los cuales las barreras culturales y de lenguaje son mínimas"(Galperin, 1999:65). Hasta tal punto este flujo (unidireccional) está "naturalizado" en la Argentina que la venta a estos países no se realiza a través de un departamento de comercialización internacional, sino que es el departamento de ventas "nacional", que, además de venderles a señales del interior, también lo hace a Paraguay y Uruguay (Mazziotti, 1996). De alguna manera, la proximidad territorial y cultural, y el escaso desarrollo de las industrias audiovisuales en esos países, permitieron estas operaciones.

Según Sergio Waisbord, estos flujos entre países latinoamericanos, como la presencia argentina en la televisión uruguaya y paraguaya "se explican por razones estrictamente económicas y de mercadeo. Grupos mexicanos (...) 
tienen aseguradas bocas de salida al ser propietarios de canales en varios países centroamericanos; tuvieron la ventaja de ser first-movers como vendedores de programas en mercados en formación y pequeños, y han comercializado agresivamente sus producciones desplazando a posibles competidores. Sin embargo, factores culturales también explican la aceptación de programas de algunos (y no todos) los países. En los ejemplos mencionados, las audiencias locales están familiarizadas con la televisión de esos países y aceptan sus acentos" (2000: 15-16).

\section{Metodología empleada}

- Se focalizó el análisis en la programación de los canales abiertos, comerciales y de programación generalista de alcance nacional de los países del Mercosur:

Argentina:

2 (América), 9 (Azul), 11 (TELEFE) y 13;

Brasil:

Globo, Bandeirantes, Rede TV, Record, y SBT;

Paraguay: 4,9 y 13 ;

Uruguay: 4,10 y 12 .

Esta elección se funda en el hecho de que la televisión comercial es el modo de producción televisiva hegemónica en América Latina y de que, pese a las particularidades de Argentina con respecto a la conexión al cable, aun en este caso la televisión abierta conserva los más altos niveles de audiencia y también su poder de dirigirse a públicos masivos.

Se seleccionó la semana del 15 al 21 de agosto y sobre ese período se trabajó con la parrilla de programación de cada país sumando las horas de programación semanal de los canales mencionados en cada caso desde las 6.00 (aproximadamente el inicio de transmisión por la mañana) hasta las 00.00 horas de cada día. Si bien Brasil tiene canales con programación en las 24 horas, se unificaron las bandas horarias a fin de poder establecer una comparación sobre una base representativa.

- El análisis se centra por un lado en la oferta total de programación (con las limitaciones ya planteadas), y por otro en la oferta durante el prime time (horario central) de lunes a viernes, dado que es la franja que supone mayores audiencias y además muestra en estos países una notable homogeneización diaria, tendencia que ha venido en aumento tanto en Argentina (Mazziotti, 1998) como en el resto de los países-miembro, pero que no es la que se presenta necesariamente en todo el mundo.

Se trabajó con la siguiente clasificación genérica, armada a partir de Tremblay y Gauvreau (1995). La televisión se tomó también como boca de emisión, dado que se computaron las películas.

\section{Información}

1.1 Periodísticos (Noticieros, entrevistas, opinión, análisis)

1.2 Educativos

1.3 Religiosos ${ }^{3}$

2. Entretenimiento

2.1 Ficción

2.1.1 Cine (corto y largo metraje, MTM (Made for Television Movie) o telefilm. 


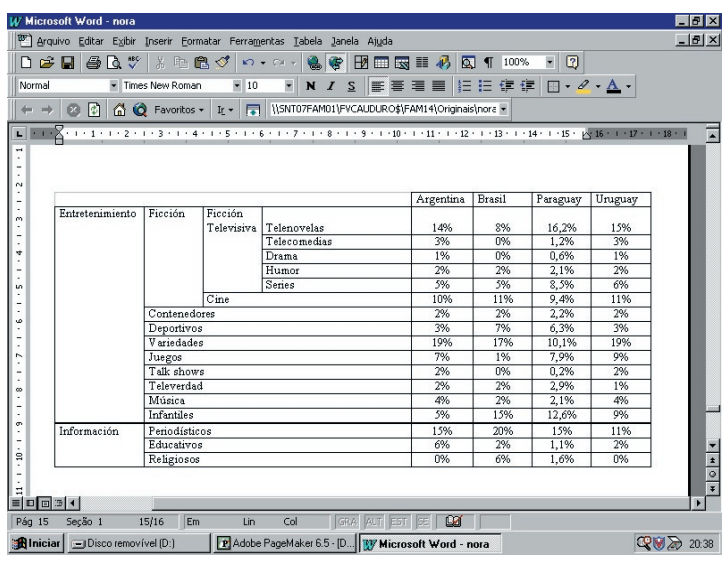

2.1.2 Ficción Televisiva

Telenovela

Telecomedia

Series

Drama (Unitario)

Hum

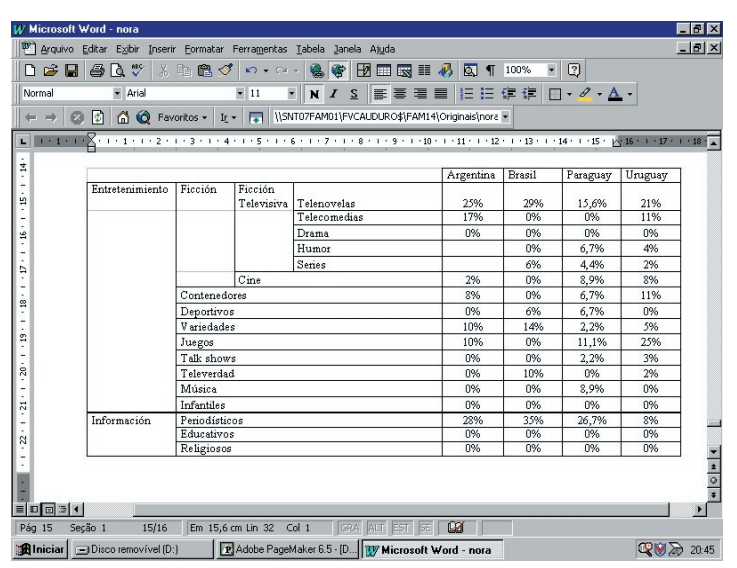

or

\subsection{Programas contenedores}

(incluyen varios tipos: interés general, entrevistas)

2.3 Deportivos (Trasmisión de un evento y periodístico-deportivo)

2.4 Variedades (chismes, magazines, culinarios)

\subsection{Juegos, concursos}

2.7 Televerdad (reality shows, programas de búsqueda de personas)

\subsection{Musicales}

2.9 Infantiles (con conductora o dibujos animados)

III Análisis de las grillas televisivas de los países-miembro del Mercosur

III.1 Programación general (lunes a domingo)

Se debe señalar, en primer lugar, que tanto en Brasil como en Argentina, el $80 \%$ de la programación es de origen nacional, mientras que en Paraguay es el $58 \%$ y en Uruguay el $49 \%$. En los dos últimos países, implica un crecimiento frente a los porcentajes señalados por Galperin, que marcaban un $70 \%$ de programación extranjera según datos de 1996 (Galperin, 1999).

Una observación surge de la comparación entre la proporción que guarda en cada país la gran división "información/entretenimiento" planteada:

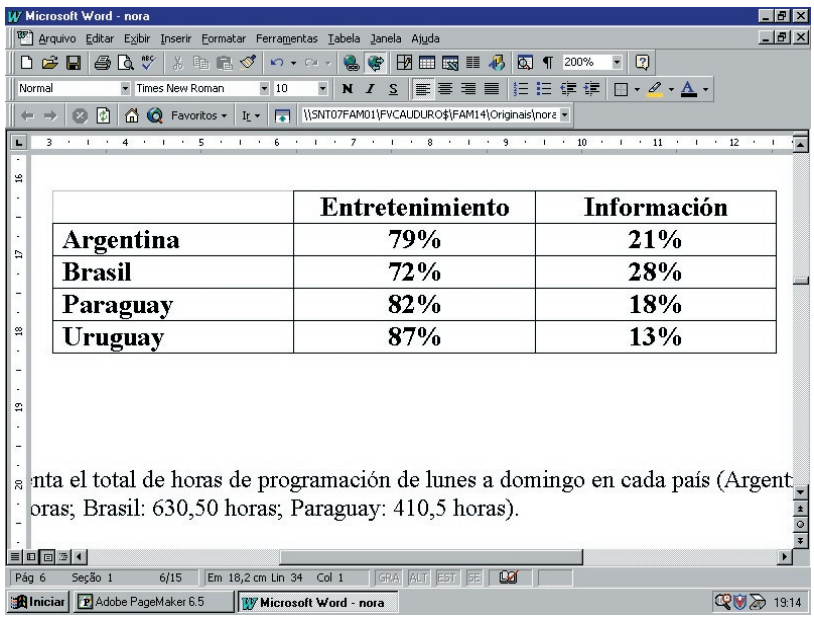

Cuadro 1. Porcentajes de programación de entretenimiento e Información en los países del Mercosur (tomando en cuenta el total de horas de programación de lunes a domingo en cada país (Argentina: 401 horas; Uruguay:

2.6 Talk shows 
354,5 horas; Brasil: 630,50 horas; Paraguay: 410,5 horas)).

Es posible observar el fuerte predominio del Entretenimiento por sobre la Información. La TV se programa para la distensión, el ocio. La narración por sobre la argumentación. Se puede inferir que la información queda para la radio. Tal vez eso explique los porcentajes significativamente pequeños en Uruguay, que tiene una radio -y hábitos de escucha- muy desarrollados y la televisión no compite con el periodismo gráfico o con cuatro señales satelitales nacionales informativas como sucede en la Argentina. También es destacable la situación inversa en el caso brasileño, donde los géneros informativos ganan terreno en comparación al resto.

El bajo desarrollo del periodismo gráfico debido al analfabetismo histórico puede tener que ver con ello. Más adelante se verá que en el prime time estos porcentajes sufren modificaciones notables en algunos casos.

Por otro lado, hay que señalar que, de acuerdo a lo que se afirmó en la introducción, el $100 \%$ de los géneros informativos en los cuatro países es producido a nivel nacional e incluso local, lo cual refrenda el hecho de que en la televisión abierta es el entretenimiento y en particular la ficción- el que presenta posibilidades para la expansión de la industria más allá de las fronteras nacionales.

En el terreno del entretenimiento se procedió a una comparación del origen de la producción de los programas que entran en esa categoría en cada país (véase en "Metodología empleada" los géneros que abarca la categoria general de entretenimiento):

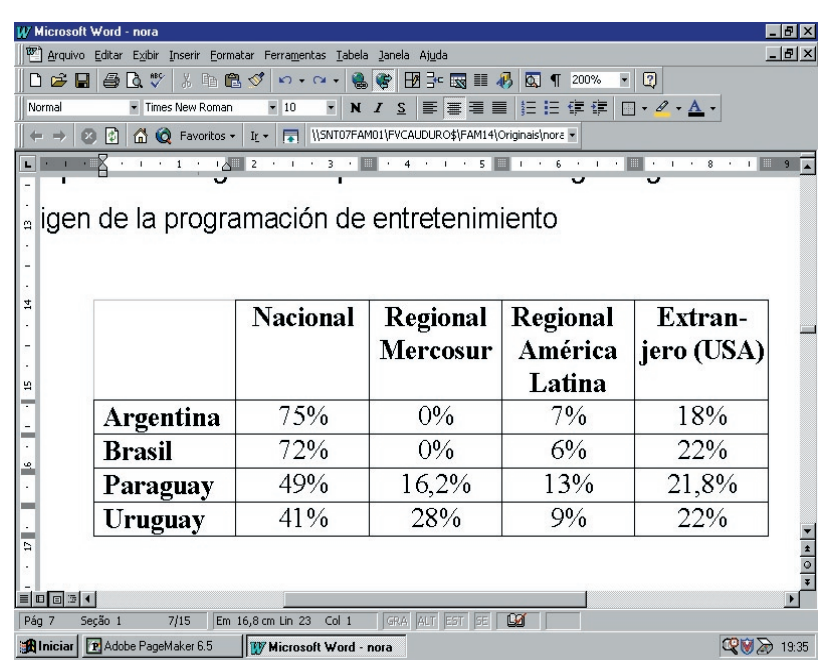

Cuadro 2. Origen de la programación de entretenimiento

La descomposición de la programación de entretenimiento según origen permite visualizar una vez más lo sostenido por diversos autores (Sinclair et al., 1996; Waisbord, 2000; Achúgar y Bustamante, 1996) respecto del avance de la producción local.

El predominio de las producciones estadounidenses en las etapas iniciales de la industria fue paulatinamente reemplazado por programación local y, en aquellos países que no desarrollaron centros de producción audiovisual, por programación regional de la misma "región geolingüística” (Sinclair et al., 1996).

Esto queda claramente ejemplificado con la llamativa homogeneidad de la columna que indica el origen estadounidense de las producciones, prácticamente restringidas a películas y series (en menor medida) como regla general en los cuatro países.

Respecto de la producción netamente nacional, en cambio, se advierte una configuración en dos pares contrastantes: Brasil y Argentina (con un $72 \%$ y un $75 \%$ respectivamente) exhiben porcentajes muy cercanos de producción nacional, mientras 
que en Paraguay (49\%) y Uruguay (41\%) se da un marcado descenso respecto de estos números.

No obstante estas diferencias, las cifras de estos últimos dos países pueden considerarse altas si se piensa en el escaso desarrollo de la industria audiovisual en ambos países.

Como ya adelantáramos, el análisis particularizado de la ficción será especialmente productivo debido al rol movilizador de ésta en el desarrollo de la industria audiovisual. (Portales, 1987).

Además de generar numerosos puestos de trabajo, permite el desarrollo de la industria de la publicidad, del star system, del periodismo de espectáculos (Mazziotti, 1996).

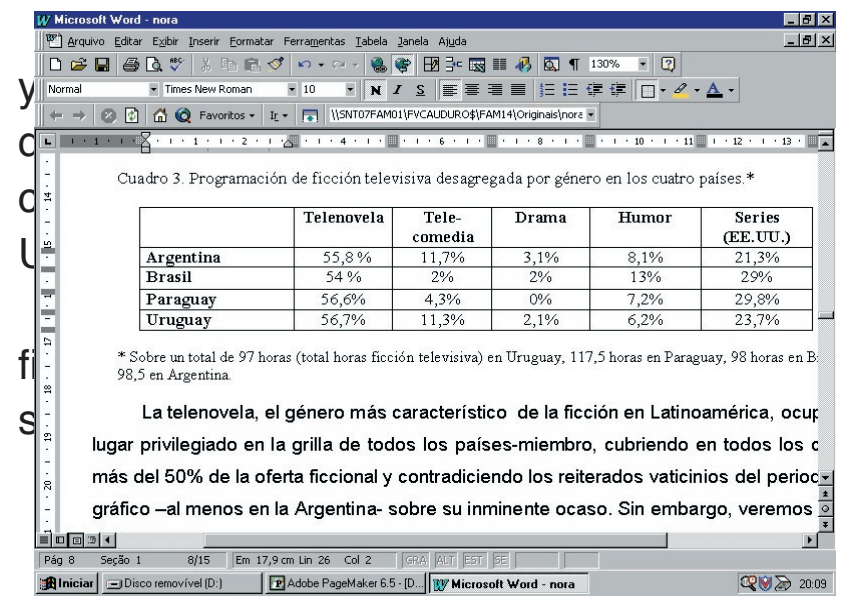

Cuadro 3. Programación de ficción televisiva desagregada por género en los cuatro países (sobre un total de 97 horas (total horas ficción televisiva) en Uruguay, 117,5 horas en Paraguay, 98 horas en Brasil y 98,5 en Argentina.

La telenovela, el género más característico de la ficción en Latinoamérica, ocupa un lugar privilegiado en la grilla de todos los países-miembro, cubriendo en todos los casos más del $50 \%$ de la oferta ficcional y contradiciendo los reiterados vaticinios del periodismo gráfico -al menos en la Argentina- sobre su inminente ocaso. Sin embargo, veremos en el punto dedicado al prime time que el género allí mostrará particularidades distintas en cada caso. Por otra parte, no obstante su retroceso respecto de otros períodos, las series estadounidenses mantienen un importante segundo lugar en la programación ficcional, con diferencias entre países: el punto más bajo se encuentra en Argentina (21\%) y el más alto en Paraguay $(29,8 \%)$. Se debe recordar que en la Argentina se ven al menos cinco señales de cable cuya programación está total o parcialmente compuesta por series.

Por tratarse del género privilegiado en la ficción de los países analizados, se indagará en el origen de los títulos de telenovelas que se ofertan:

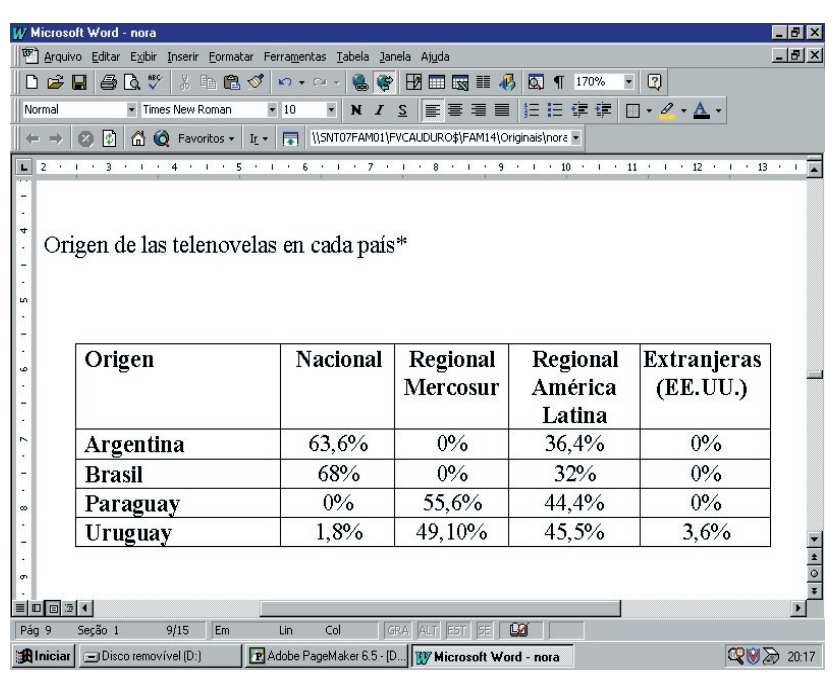

Cuadro 4. Origen de las telenovelas en cada país (sobre un total de horas de telenovela de 55 en Argentina, 53 en Brasil, 66,5 en Paraguay y 55 en Uruguay).

Como se adelantó en la introducción, encontramos dos países que tienen una larga tradición como productores de programación, como Brasil y Argentina, y dos países que deben importar prácticamente la totalidad de su programación de ficción y en particular de telenovelas. Sin embargo, además de esta afirmación general caben dos observaciones: en primer lugar, la incipiente producción ficcional en Uruguay (producen una telenovela, El año del dragón, emitida con frecuencia semanal) podría estar marcando una tendencia, o al menos un intento de puesta en marcha de la industria. 
En segundo lugar, la diferencia señalada entre Brasil y Argentina al comienzo no parece influir en el porcentaje de producción nacional de telenovelas, signific ativamente similar en ambos casos.

Por otra parte, en el Mercosur la hegemonía televisiva la tiene la Argentina, donde la situación ventajosa de Brasil a nivel mundial se invierte: en Paraguay el $73 \%$ de las telenovelas procedentes del Mercosur son argentinas.

Y en Uruguay la cifra asciende al $89 \%$, si bien presenta un descenso en el prime time, como se verá en el siguiente punto.

Por otro lado, la presencia argentina se profundiza si se toma la totalidad de la programación originada en el Mercosur en los dos países importadores: $82 \%$ en Paraguay y $96 \%$ en Uruguay.

También, es sugestiva -aunque no novedosa- la ausencia total de novelas argentinas en Brasil, y viceversa ${ }^{4}$.

Hay un caso interesante para el análisis que es el de la migración de formato, como sucede con Chiquititas, originalmente una telenovela infantil de origen argentino, con la que se realizó una joint-venture entre Telefé y SBT.

Sin embargo, no será desarrollado en el presente trabajo, dado que éste se centra en la circulación definida en términos más restringidos (circulación del programa tal como fue originalmente emitido).

\section{III.2 Prime time (lunes a viernes)}

Mientras que en el punto anterior el análisis abarcó la totalidad de la programación semanal, en éste se focalizará en la programación de horario central, que presenta pequeñas diferencias en su determinación en cada país.

Mientras que en Argentina, Paraguay y Uruguay se considera como horario central la franja de 20.00 a 23.00 horas, en Brasil se toma sólo hasta las 22.00.

El horario central se define por la cantidad de audiencia que convoca el medio en ella, condición que determina el aumento de las tarifas publicitarias en esa franja.

El análisis de la oferta en el prime time llevará a mayores precisiones.

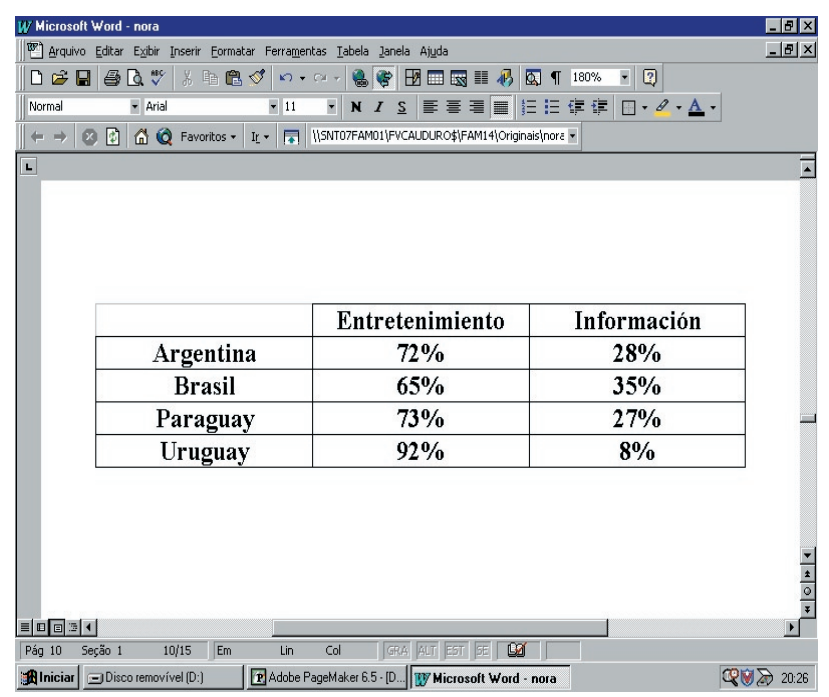

Cuadro 5. Porcentajes de programación de entretenimiento e Información en el prime time (lu-vi) en los países del Mercosur

Si se compara el cuadro 5 con el 1 (véase punto anterior), observamos que se modifican levemente las tendencias ya señaladas: mientras que en Argentina y Brasil disminuye, aunque no muy significativamente, el peso de la ficción, y Paraguay muestra cierta preferencia por la información (pasa de un 18\% en la programación total a un $27 \%$ en el prime time), Uruguay invierte la tendencia de los otros países y programa apenas un $8 \%$ de información en el prime time de Lunes a Viernes.

Este detalle tendrá una incidencia inevitable en la composición del origen de la programación, ya que como se señaló, la información es en su totalidad producida a nivel nacional en todos los países, mientras que no sucede lo mismo con el entretenimiento. De allí que en el prime time la producción nacional uruguaya llegue apenas a un $20 \%$, mientras que en Argentina alcanza un $97 \%$. 
La cifra considerablemente menor en Brasil (72\%) está influida por un porcentaje importante de programación de origen latinoamericano (fundamentalmente de México) en el prime time, hecho que marca una diferencia con los otros tres países, que si bien incluyen programación regional de América Latina en sus grillas generales - telenovela de México, en menor medida Venezuela, y recientemente, Perú (véase Cuadro 2)-, la ubican en horarios de menor audiencia.

En esta particularidad sin duda opera la política de importación de novelas mexicanas llevada adelante por la SBT, que intentó (en algunos casos con notable éxito) competir por esta vía con las cuidadas producciones de la Rede Globo.

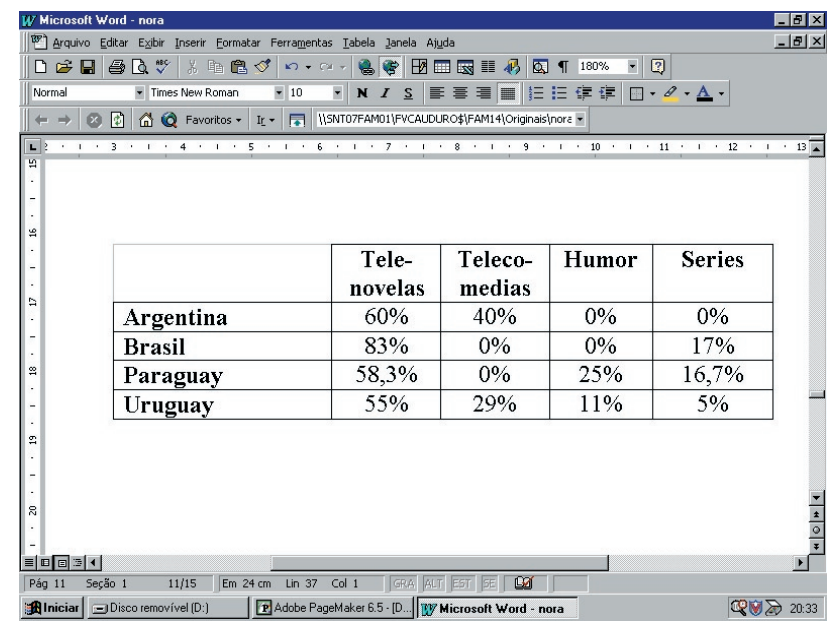

Cuadro 6. Proporción de géneros presentes en la ficción televisiva del prime time

La telenovela se afianza decididamente como preferencia dentro de la ficción en el prime time brasileño, con un $83 \%$ (frente al $54 \%$ que presentaba en la programación en general, véase Cuadro 3). En Argentina y Uruguay el género no presenta demasiados cambios respecto de la programación general, salvo si se considera el origen de los títulos: en Uruguay el porcentaje de $89 \%$ para las telenovelas argentinas dentro de los títulos provenientes del Mercosur señalado para la programación en general disminuye a un $79 \%$. Las producciones brasileñas, con una larga tradición de emisión en la televisión abierta uruguaya -en 1979 la Globo dobla para su venta a Uruguay O Bem Amado (Mazziotti, 1996)- recuperan espacio, aunque se trate sólo de un título, en el prime time.

En Argentina y Uruguay, la telecomedia muestra un aumento elocuente $(40 \%$ y $29 \%$ respectivamente) y las series estadounidenses alcanzan un porcentaje significativamente más bajo (llega a desaparecer totalmente en el caso argentino) que en Paraguay y en Brasil. En el caso argentino, el marcado retroceso de las series del horario central de la televisión abierta sin duda está relacionado con el avance del cable: las series, dado que llegan en el cable con episodios más recientes, ya no constituyen un atractivo para grandes públicos.

\section{Conclusiones}

En el punto anterior se intentó reflexionar sobre los rasgos más destacados surgidos del análisis de las grillas de programación en cada país-miembro, así como del cotejo de esas grillas entre sí. Por otra parte, debido a que el objetivo del trabajo era de manera fundamental la indagación de las tendencias en la circulación, se focalizó especialmente en el origen de las producciones emitidas.

El análisis propuesto se centró en gran medida en la programación de entretenimiento debido a varias razones, una de ellas es su ya subrayado rol en el desarrollo de la industria y otra el fuerte predominio respecto de la información que presenta en las grillas de todos los países, aun con sus particularidades en cada uno. En el campo del entretenimiento, entonces, se acentúa la marcada asimetría entre los países-miembro en cuanto a la capacidad de producción y exportación de programas. Por un lado, Brasil y 
Argentina, que importan algo más de un $20 \%$ de su programación y por otro Paraguay y Uruguay, que deben recurrir a la importación en proporciones mucho mayores, fundamentalmente en el campo de la ficción.

En relación con el párrafo anterior, otro de los aspectos más importantes señalados responde a una situación que antecede al Tratado: por razones de «proximidad cultural», las grillas paraguayas y uruguayas incorporan un altísimo porcentaje de programación argentina, frente a uno muy bajo de programación brasileña. Es de destacar en este sentido, el rol de importancia de la industria argentina en el área. Inclusive, programas uruguayos del rubro juegos o variedades, son de producción argentina.

En Argentina, en muchas ocasiones el análisis marcó la alta tasa de conexión al cable como explicación de algunas de las particularidades que exhibe la grilla, como una mayor producción nacional de ficción que Brasil, pese a la mucha mayor presencia que tiene este último a nivel mundial.

Una de las conclusiones evidentes a partir del estudio desarrollado es el claro avance de la programación de origen local, no sólo en áreas donde tradicionalmente es fuerte, como la información, sino también en el entretenimiento. Además del ya mencionado porcentaje de más de un $70 \%$ de producción nacional de entretenimiento en Argentina y Brasil, por un lado se halla una producción relevante (en términos de carga horaria) de programas de variedades y talk shows en Paraguay y Uruguay ( a pesar de que la producción sea argentina, en algunos casos en Uruguay, como se dijo) y por otro, la producción de una telenovela en este último país. En el primer caso, se debe hacer la salvedad de que se trata de programas de bajo costo que no representan una movilización de otros rubros de la industria; en el segundo, si se tratara de una tendencia y no apenas un caso aislado, podría marcar cambios en la futura composición de la grilla uruguaya.

Por otra parte, al señalar un «avance la producción nacional/local», pretendemos marcar un cambio respecto de años anteriores, pero de ninguna manera sugerir que en un nivel más estructural hubiera una menor influencia de modalidades de producción mundialmente hegemónicas.

Como sostienen Sinclair et al. (1996), contrariamente a lo que se pensó durante años, la impronta más fuerte de los Estados Unidos en el desarrollo de la televisión mundial no es la influencia a través de los programas en sí, sino del modelo sistémico implantado: la explotación de la programación de entretenimiento como forma de atraer audiencias que pudieran luego ser vendidas a anunciantes. En coherencia con este rasgo, la circulación de programación entre los países que analizamos se viene dando de manera colateral -y previa- al Tratado, dado que se sustenta en razones puramente comerciales y no tiene relación alguna con políticas de integración regional .

\section{Notas}

1 Este texto se inscribe en el Proyecto Ubacyt TS 15, "Procesos comunicacionales y mediaciones interculturales en el Mercosur. Estudio de casos críticos y relevantes en situaciones de comunicación directa y comunicación mediatizada", dirigido por Aníbal Ford, con asiento en el Instituto de Investigación Gino Germani, Facultad de Ciencias Sociales, Universidad de Buenos Aires.

2 Agradecemos a Luciana Andión, que paciente y meticulosamente nos informó sobre la programación uruguaya, y a Hugo Olazar y Aníbal Orué Pozzo, por la colaboración sobre la TV en Paraguay.

3 Se optó por colocar los programas de este tipo en información, sabiendo que puede dar lugar a cuestionamientos. Algunos programas actuales, sobre todo en la TV brasileña, conducidos por predicadores, podrían ubicarse en Entretenimiento.

4 Sobre la ausencia de telenovelas brasileñas en la 
Argentina, a pesar de haberse emitido con éxito a fines de los 70, véase Mazziotti, 1996.

\section{Referências}

ACHUGAR, H., Bustamante, F(1996): "Mercosur, intercambio cultural y perfiles de un imaginario". En García Canclini, N. (coord.): Culturas en globalización. América Latina - Europa - Estados Unidos: libre comercio e integración. Caracas, Nueva Sociedad.

BUSTAMANTE, E. (1994): "Audiovisual integrado, política global". En Parés y Maicas, M. (comp.): Cultura y comunicación social: América Latina y Europa Ibérica. Generalitat de Catalunya, Centre d'Investigació de la Comunicació y Universitat Autónoma de Barcelona.

CROVI DRUETTA, D. (coord) (1995): Desarrollo de las industrias culturales audiovisuales en México y Canadá. México, Universidad Autónoma de México.

FORD, A., S. Martini y N. Mazziotti (1996): "Construcciones de la información por la prensa argentina sobre el Tratado del Mercosur". En García Canclini, N. (coord.): Culturas en globalización. América Latina- Europa - Estados Unidos: libre comercio e integración. Caracas, Nueva Sociedad/ CLACSO.

GALPERIN, H. (1997): "Las industrias culturales en los acuerdos de integración regional. El caso del TLCAN, la UE y el Mercosur". En Comunicación y Sociedad, México, No. 31, set.-dic.

. H (1999): "Cultural industries in the Age of Free-Trade Agreements" en Canadian Journal of Communication, Vol.24:49-77.

MAZZIOTTI, N.: La industria de la telenovela. La producción de ficción en Amériaca Latina. Buenos Aires, Paidós, 1996.

MAZZIOTTI, N (1998) "All that Rating Allows. Fiction and Market in Argentine Television." Paper leído en las $2^{\text {nd }}$. Tel Aviv International Colloquium in Cinema Studies, "La longue durée. Framing in Series, Serials and Other Macaroni Forms". Departament of Film and Television, Faculty of the Arts, Universidad de Tel Aviv.
MURCIANO, M. (1996) "Las políticas de comunicación europeas. Análisis de una experiencia en desarrollo". En Comunicación y Sociedad, Guadalajara, № 28, set.-dic.

PORTALES, D. (1987): La dificultad de innovar. Un estudio sobre empresas de televisión en América latina. Santiago, ILET.

RONCAGLIOLO, R. (1994):"Las atipicidades de la televisión latinoamericana" en Parés i Maicas, M. (comp) Cultura y comunicación social: América latina y Europa Ibérica, Generalitat de Catalunya, Centre d'Investigació de la Comunicació i Universitat Autónoma de Barcelona.

SÁNCHEZ Ruiz, E. (1993): "El espacio audiovisual mexicano ante el Acuerdo de Libre Comercio Canadá-Estados Unidos- México". En Intercom. Revista Brasileira de Comunicaçâo. Sâo Paulo, Vol XVI, Nº1, janeiro/junho.

SINCLAIR, J.; E. Jacka y S. Cunningham (eds.) (1996) New Patterns in Global Television, New York, Oxford University Press.

TREMBLAY, G y Gauvreau, C. (1995) En Crovi Druetta, (1995)

WAISBORD, S.: "Industria global, culturas y políticas locales: la internacionalización de la televisión latinoamericana" Ponencia presentada en el $\mathrm{V}$ Encuentro ALAIC, en Santiago, Chile, abril de 2000.

\section{Anexos}

1. Programación general (lunes a domingo) desagregada en géneros

2. Programación del prime time (lunes a viernes) desagregada en géneros. 